\title{
Paratesticular Wilms Tumor
}

National Cancer Institute

\section{Source}

National Cancer Institute. Paratesticular Wilms Tumor. NCI Thesaurus. Code C162489.

A rare Wilms tumor that arises from the paratesticular structures. 